Research Article

\title{
Effect of Compressive Strain of Brake Pads on Brake Noise
}

\author{
Yihong Gu $\mathbb{D}^{1,2}$ Yucheng Liu $\mathbb{D},{ }^{3,4}$ Congda Lu $\mathbb{D},{ }^{1}$ Shugen $\mathrm{Hu} \mathbb{D},{ }^{5}$ and Xiaowen Song $\mathbb{D}^{5}$ \\ ${ }^{1}$ College of Mechanical Engineering, Zhejiang University of Technology, Hangzhou 310014, China \\ ${ }^{2}$ Quzhou College of Technology, Quzhou 324000, China \\ ${ }^{3}$ Zhejiang Wanda Steering Gear Co., Ltd., Hangzhou 311258, China \\ ${ }^{4}$ College of Energy Engineering, Zhejiang University, Hangzhou 310023, China \\ ${ }^{5}$ School of Mechanical Engineering, Zhejiang University, Hangzhou 310023, China \\ Correspondence should be addressed to Congda Lu; lcd@zjut.edu.cn
}

Received 3 July 2020; Revised 9 October 2020; Accepted 7 November 2020; Published 23 November 2020

Academic Editor: Wahyu Caesarendra

Copyright (c) 2020 Yihong Gu et al. This is an open access article distributed under the Creative Commons Attribution License, which permits unrestricted use, distribution, and reproduction in any medium, provided the original work is properly cited.

Brake noise, a principal component of vehicle noise, is among the most critical measures of vehicle quality. The perceived quality of cars can be improved by reducing brake noise; therefore, vehicle manufacturers are extensively investigating the influencing factors, generating mechanism, and solutions of brake noise. Compressive strain is one of the most influential performance parameters of a brake pad and can be adjusted by regulating the material elastic modulus and by modifying the shape of the brake lining. In this study, the compressive strain of a brake pad was adjusted through four methods, and the noise characteristics of brake pads with different elastic modulus, section outlines, lining widths, and chamfers were studied through finite element analysis and the complex-eigenvalue method. The effects of compressive strain of a brake pad on brake noise were examined, and an optimized brake-pad scheme was developed. A dynamometer test conducted to validate the effectiveness of the optimized scheme confirmed a clear alleviation in brake noise.

\section{Introduction}

Brake noise, particularly high-frequency brake squeal, is one of the principal components of vehicle noise; it can cause noise pollution and directly affect ride comfort [1]. With increase in the number of automobiles, the detrimental effects of brake noise on the environment are becoming increasingly severe. Disk brake, the most common brake system, is widely used in passenger cars and light commercial vehicles. The ride comfort of a vehicle can be substantially improved by reducing brake noise; therefore, noise control of disk brakes has become a focal research area in vehicle noise, vibration, and harshness (NVH) engineering. In addition, noise control is currently a crucial concern in the design and development of brake systems and automobiles in general [2].

Brake systems-in particular, the geometrical characteristics and material properties of brake-system components-are typically modeled and analyzed through finite element analysis, primarily the frequency-domain complex- eigenvalue method and transient state dynamics analysis [3]; the former was first developed in the 1980s and has since become one of the most widely used approaches in brake design for predicting brake noise [4]. Numerous studies have investigated the effects of geometrical characteristics (e.g., the geometry, structure, wear, and slots of brake lining [5-8]) and material properties (e.g., elastic modulus, damping, frictional coefficients, and surface characteristics of brake-friction materials [9-12]) of brake pads on brake noise. Because of the complexity of brake-noise analysis, these studies have each examined one or two of the listed factors individually, meaning that different noise reduction methods are yet to be compared in the literature given the lack of unified parameters.

Compressive strain is a major index of brake-pad properties and is defined as the ratio of the compression load-induced reduction in the thickness of a brake pad to its initial thickness; it is measured along the direction of the applied force (i.e., perpendicular to the friction surface); it is useful in evaluating brake-fluid displacement during braking 
as well as brake-pedal travel and the propensity of the brake to generate judder or noise [13]. Compressive strain is an external physical property of a brake pad; thus, it can be adjusted not only by regulating the elastic modulus of the friction material but also by modifying the section outline, lining width, or chamfer dimensions of the brake lining. Adjusting of the compressive strain will change the stiffness, which lead to the variation of stiffness and modal of the brake system and affect the NVH performance during vehicle braking. Thus, it is necessary to study the influence of compression strain on brake noise, so as to optimize the lining parameters and solve the brake-noise problem of existing products.

In this study, compressive strain was used as the unified parameter; it was regulated through various technical methods, and the consequent effects on noise reduction were compared. Moreover, the assembly of brake systems equipped with pads with different structural and material properties was analyzed through the finite element and complex-eigenvalue methods, and the effect of these brake pads on brake noise was studied.

\section{Analysis of Brake Noise through the Finite Element Method}

For a general vibrating system, the equation of vibration can be expressed as follows:

$$
M \ddot{x}+C \dot{x}+K x=F,
$$

where $M, C$, and $K$ are the mass, damping, and stiffness matrices of the vibration system, respectively, and $x$ is the displacement vector. For a brake system, the forcing function $F$ is assumed to be mainly contributed by the variable friction force at the lining-disk interface, which can be expressed as follows [7]:

$$
F=\mu K_{f} \cdot x
$$

where $\mu$ is the friction coefficient between the brake lining and disk and $K_{f}$ is the friction stiffness matrix. Combining equations (1) and (2) yields the following homogeneous equation [14]:

$$
M \ddot{x}+C \dot{x}+\left(K-\mu K_{f}\right) x=0,
$$

where because of the friction force, the system stiffness is coupled and the stiffness matrix is asymmetric, which in turn results in asymmetry of the characteristic matrix. Therefore, the eigenvalues of the characteristic matrix might be complex under certain conditions. For an underdamped system, the eigenvalues always occur as complex-conjugate pairs. The characteristic equation is

$$
\begin{aligned}
\operatorname{det}\left(\lambda^{2} M+\lambda C+K-\mu K_{f}\right) & =0, \\
\lambda_{i 1,2} & =\sigma_{i} \pm j \omega_{i},
\end{aligned}
$$

where $\lambda_{i}$ is the eigenvalue of the $i^{\text {th }}$ mode of the system, $\sigma_{i}$ is the real part of the eigenvalue and represents the attenuation coefficient of the corresponding mode, and $\omega_{i}$ is the imaginary part of the eigenvalue and represents the natural angular frequency of the corresponding mode. The damping ratio of corresponding mode is

$$
\zeta_{i}=-\frac{\sigma_{i}}{\omega_{i}}
$$

Therefore, the stability of the system can be determined on the basis of whether $\sigma$ is positive or negative. If $\sigma_{i}<0$, the damping ratio is positive, the system vibration decays over time and the system is stable. If $\sigma_{i}>0$, the damping ratio is negative, the system vibration does not decay over time, and therefore the corresponding mode is unstable; in this condition, the absolute value of the damping ratio reflects system instability, and a higher value indicates a higher probability of brake noise [15].

The brake system of a passenger car's front axle was chosen as the research object in this study. This typical brake system has the common form of a single piston, sliding caliper, and ventilated disc. After simplification, the finite element model of the brake system was established using Hypermesh 13.0 (Figure 1). The quadratic tetrahedral C3D10M element, which can be easily applied to complex geometries and exhibits high-simulation performance in the frequency domain, was used as the mesh element [16]. The entire brake system was meshed using 151,942 elements of size $3-5 \mathrm{~mm}$.

Table 1 lists the properties of each component in the brake system finite element model. The material properties were provided by the manufacturers, and the property of brake lining was also confirmed through compression tests. Table 2 lists all interactions existing in any brake system; in this study, the tie and surf-surf contact interactions were used to simulate the contact relationship between the various surfaces. Brake noise is affected by the friction coefficient between the disk and lining; the nominal friction coefficient provided by the friction-material manufacturer (and corrected through dynamometer tests) was used in the present analysis. In the finite element model, the friction coefficients of interactions corresponding to cast iron-NAO, steel-steel, steel-cast iron without lubrication, and steel-cast iron with lubrication were defined as $0.48,0.10,0.16$, and 0.05 , respectively.

Figure 2 presents the boundary conditions of the analysis; the bracket of the brake system is fixed on the knuckle by using its threaded hole; thus, the inner surface of both threaded holes is restricted in the model. The disk is clamped to the wheel hub and the knuckle by using screws; thus, the inner and outer surfaces of the disk's convex plate are restricted. According to the dynamometer test result, the braking noise mainly occurs in the constant speed drag condition of $3 \mathrm{~km} / \mathrm{h}$, which corresponds with the brake pressure of $3 \mathrm{Mpa}$. Thus, a load of $3 \mathrm{MPa}$ is applied on the end face of the piston to simulate brake pressure, and the rotational motion of the disc with an equivalent linear velocity of $3 \mathrm{~km} / \mathrm{h}$ is defined using the keywords MOTION 


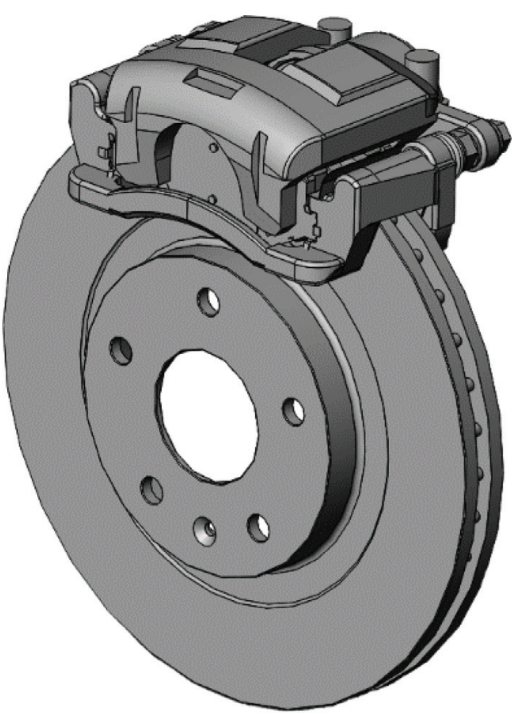

(a)

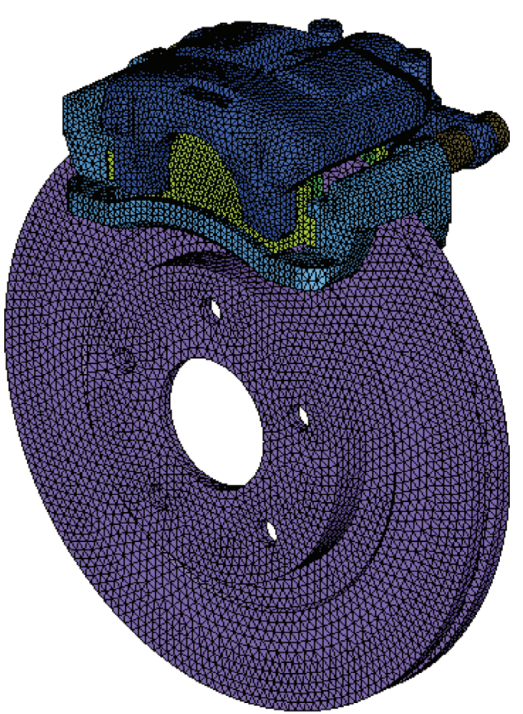

(b)

FIgURE 1: Original and finite element model of the brake system.

Table 1: Properties of components in the brake system finite element model.

\begin{tabular}{|c|c|c|c|c|c|c|c|}
\hline Components & Material & Density $\rho /\left(10^{3} \mathrm{~kg} / \mathrm{m}^{3}\right)$ & $\begin{array}{l}\text { Elastic modulus } \\
(E / \mathrm{MPa})\end{array}$ & Poisson ratio $v$ & Element type & Element size $(s / \mathrm{mm})$ & Element number \\
\hline Disc & HT250 & 7.15 & 120000 & 0.26 & C3D8R & 5.0 & 46829 \\
\hline Caliper & QT450 & 6.86 & 173500 & 0.30 & C3D8R & 3.5 & 43379 \\
\hline Bracket & QT450 & 6.86 & 173500 & 0.30 & C3D8R & 3.5 & 20451 \\
\hline Piston & $35 \#$ & 7.85 & 212000 & 0.31 & C3D8R & 3.0 & 3945 \\
\hline Pin & Q345 & 7.85 & 206000 & 0.28 & C3D8R & 3.0 & 1594 \\
\hline Backplane & Q345 & 7.85 & 206000 & 0.28 & C3D8R & 3.0 & 5286 \\
\hline Lining & NAO & 1.61 & 709 & 0.36 & C3D8R & 3.0 & 7694 \\
\hline
\end{tabular}

TABLE 2: Interactions in the brake system finite element model.

\begin{tabular}{llcc}
\hline Contact pair & Interaction & Numbers in the model & Friction coefficient \\
\hline Backplate-bracket & Surf-surf contact & 4 & 0.16 \\
Backplate-piston & Surf-surf contact & 1 & 0.10 \\
Backplate-caliper & Surf-surf contact & 1 & 0.16 \\
Bracket-pin & Surf-surf contact & 2 & 0.05 \\
Piston-caliper & Surf-surf contact & 1 & 0.16 \\
Lining-disc & Surf-surf contact & 2 & 0.48 \\
Lining-backplate & Tie & 2 & - \\
Pin-caliper & Tie & 2 & - \\
\hline
\end{tabular}

ROTATION in the input file. After preprocessing, the brakesystem model was input to Abaqus 6.13-4, and the Lanczos method was used to extract the eigenvalues of the system.

As expressed in equation (5), the eigenvalues obtained through the complex modal analysis are complex. Based on empirical engineering experience, modes with damping ratio less than threshold $T$ were considered noisy modes. In the literature, $T$ varies from $-0.5 \%$ to $-1.0 \%[7,17,18]$; in this study, after a review of the test results, $T$ was set at $-0.6 \%$, and the resultant noisy modes are listed in Table 3. A dynamometer test was also performed according to SAE J2521 to validate the finite element method [19]; the obtained frequency distribution and sound pressure levels (SPL) are plotted in Figure 3. In the dynamometer test, brake squeal was recorded at frequencies of 7800, 8800, and $11000 \mathrm{~Hz}$. Brake noise appeared in the $3000-4400 \mathrm{~Hz}$ frequency band, but with a fragmented frequency; this behavior is due to property changes induced in the brake system because of the low temperatures used in the cold section of the test. Comparing the data in Table 3 and Figure 3 shows that most noisy modes were consistent with the frequency distribution; only the $104^{\text {th }}$ mode exhibited a $4 \%$ error in frequency. Thus, the finite element model is adequately accurate for further analysis. 




(a)

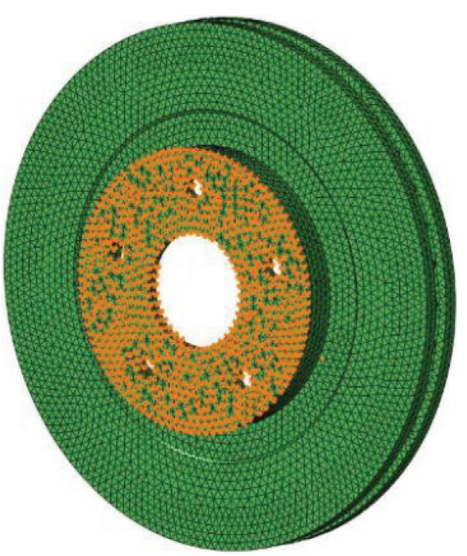

(b)

Figure 2: Bracket and disk boundary conditions.

TABLE 3: Noisy modes in the finite element analysis.

\begin{tabular}{lccc}
\hline Modal order & Natural frequency $(\mathrm{Hz})$ & Eigenvalue (real part) & Damping ratio $\left(10^{-2}\right)$ \\
\hline 64 & 3880.3 & 192.20 & -0.7883 \\
99 & 7809.3 & 307.12 & -0.6259 \\
104 & 8201.8 & 698.59 & -1.3555 \\
110 & 8837.3 & 534.63 & -0.9628 \\
134 & 10885.0 & 609.76 & -0.8915 \\
\hline
\end{tabular}



Figure 3: Noise distribution in the dynamometer test.

\section{Methods of Adjusting the Compressive Strain of Brake Pads}

Regulating the elastic modulus of brake-friction material is the most direct method of adjusting the compressive strain of a brake pad. For a given brake-pad contour, the compressive strain is directly proportional to the elastic modulus of the friction materials. Since the present brake lining is made of NAO (non-asbestos organic) material and molding using the hot pressing process, lining with different elastic modulus can be produced by adjusting the raw material powder ratio or process parameters.
In this study, compressive strain is too small a measure to reflect the differences between materials; therefore, thickness variation of linings under a pressure of $16 \mathrm{Mpa}-\mathrm{a}$ measurement point specified in ISO6310:2009-was chosen as the reference value to reflect changes in compressive strain. By varying the elastic modulus of the friction materials, 11 sets of brake-pad models of thickness variation $85-135 \mu \mathrm{m}$ were fabricated; the absolute error in thickness variation was restricted to no more than $0.05 \mu \mathrm{m}$. To simplify the model and the analysis, the nonlinear characteristics of the friction materials and backplane deformation were ignored. The process of establishing the model is depicted in Figure 4. 
The compressive strain of a brake pad can also be controlled by modifying the shape of the brake lining. However, because changes to the structure of a brake lining is restricted by the presence of the caliper and bracket, such modifications can be achieved only by removing parts of the friction material, such as by narrowing the section outline, reducing the lining width, or chamfering the pads (Figure 5). As shown in Table $4, \Delta d$ is the thickness variation of brake lining, $E$ is the elastic modulus of the brake material, $s$ is the contour distance of the lining outline, $w$ is the shrink width of the lining, and $\varphi$ is the angle of lining chamfer. The brakepad model with a thickness variation of $85 \mu \mathrm{m}$ was used as the reference model. All models were classified into four analysis groups, namely, Groups A-D, corresponding to the four methods of regulating compressive strain, namely, regulating the elastic modulus, narrowing the section outline, reducing the lining width, and chamfering the brake pads, respectively.

\section{Tendency Analysis of Brake Noise}

The brake-pad models were established according to the parameters listed in Table 4 and subject to finite element modeling; 44 sets of data were obtained. To analyze instability in each model, tendency of instability (TOI) was introduced as the stability evaluation index of the brake system [20]:

$$
\mathrm{TOI}=\sum_{i}\left(\frac{\sigma_{i}}{\omega_{i}} \cdot 1000\right), \quad \sigma_{i}>0
$$

The negative ratios of $\sigma_{i}$ and $\omega_{i}$ are the damping ratio of the corresponding mode; therefore, according to equation (7), TOI is positively correlated with system instability. Table 5 presents the number of noisy modes with damping ratio less than $-0.6 \%$ and the TOI for each model, and Figure 6 shows the TOI trend curve for each group.

Adjusting the compressive strain in Group A would result in the largest change in the number of noisy modes (Table 5); for example, note that the model with a thickness variation of $115 \mu \mathrm{m}$ has six noisy modes. The change in the number of noisy modes with compressive strain is not evident in the other three groups, where the number of noisy modes ranges from 1 to 3 . Regarding TOI, with increase in thickness variation (compressive strain), the TOI of Groups $\mathrm{B}, \mathrm{C}$, and $\mathrm{D}$ decreased whereas that of the Group A increased. Because TOI is only an index for evaluating the stability of brake systems, brake-noise distribution, including frequency and damping ratio of the noisy modes, cannot be described in Figure 6. Figures 7-10 present the extracted brake-noise distribution of all noisy modes in Groups A-D.

In Group A, the number of noisy modes first increases and then decreases with the decrease in the elastic modulus (Figure 6). Regarding noise distribution, with increase in compressive strain, a new noisy mode with an increasing damping ratio appeared at $3900 \mathrm{~Hz}$. By contrast, the

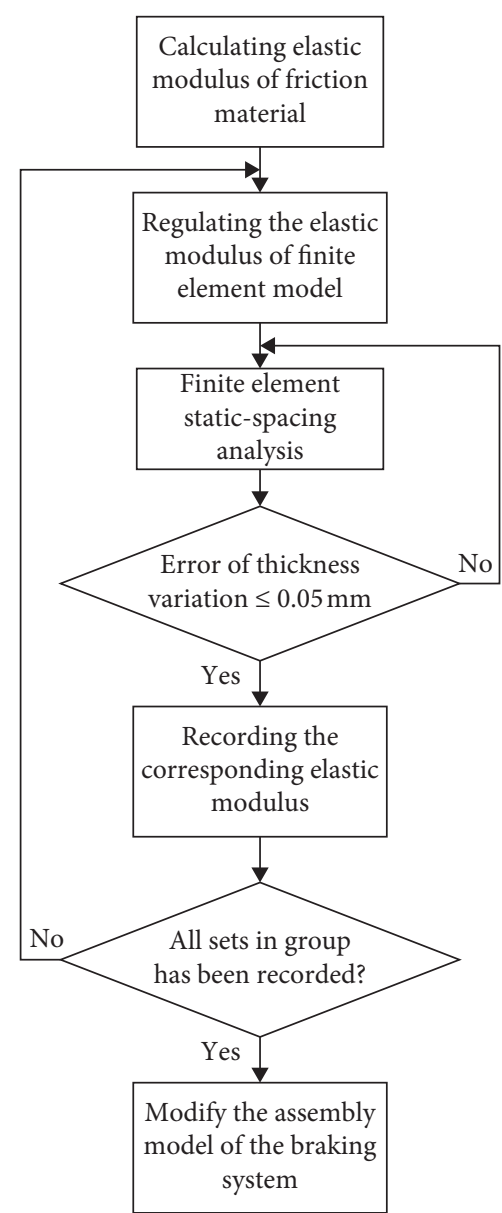

FIgURE 4: Process of adjusting the compressive strain by regulating the elastic modulus.

damping ratios of noisy modes with corresponding frequencies exceeding $7000 \mathrm{~Hz}$ decreased with increase in compressive strain, and the frequencies corresponding to these modes changed as well. In the thickness variation range of $115-125 \mu \mathrm{m}$, some noisy modes disappeared with increase in compressive strain. Accordingly, adjusting the compressive strain of the brake pad by regulating the elastic modulus of the brake-friction material may substantially affect the number of noisy modes and the distribution of brake noise. Changes in noise distribution were accompanied by decrease in the damping ratio, change in the frequency, and appearance or disappearance of noisy modes at some frequencies.

By contrast, in Figure 7, all noisy-mode frequencies in Group B were concentrated at 8600, 9100, and $9900 \mathrm{~Hz}$. Except for the noisy mode with a corresponding frequency of $8600 \mathrm{~Hz}$ that appeared only in the model with a thickness variation of $85 \mu \mathrm{m}$, the noisy modes at the other two frequencies varied as the damping ratio increased with increase in compressive strain. Therefore, changing the compressive strain by narrowing the section outlines of the brake lining has some effect on reducing brake noise, but this approach 


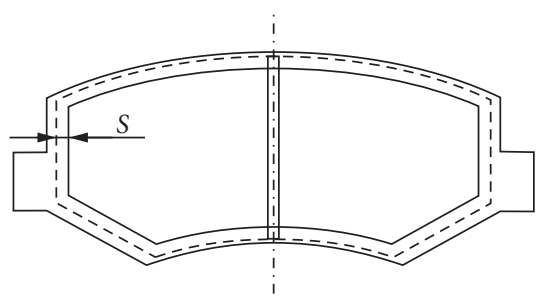

(a)

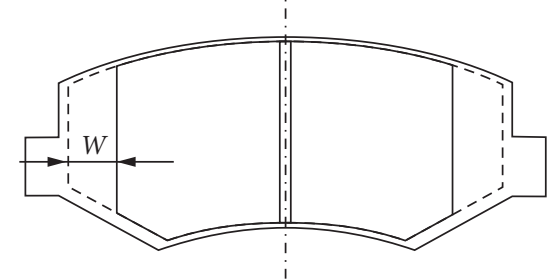

(b)

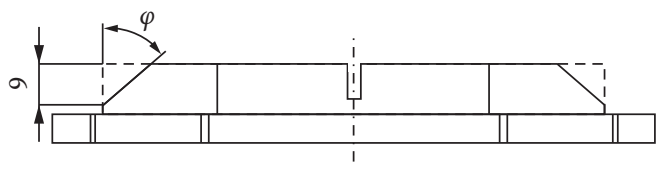

(c)

FIGURE 5: Methods of adjusting the compressive strain by modifying the brake lining: (a) narrowing the section outline; (b) reducing the lining width; (c) chamfering the brake pads.

Table 4: Parameter setting used in Groups A-D.

\begin{tabular}{lcccc}
\hline Thickness variation $\Delta d(\mu \mathrm{m})$ & Elastic modulus $E(\mu \mathrm{m})$ & Contour distance $s(\mu \mathrm{m})$ & Shrink width $w(\mu \mathrm{m})$ & Chamfer angle $\varphi($ degree $)$ \\
\hline 85 & 917.0 & 0.000 & 0.00 & 0.00 \\
90 & 866.0 & 0.820 & 4.17 & 39.99 \\
95 & 821.0 & 1.590 & 10.30 & 50.89 \\
100 & 779.5 & 2.290 & 12.56 & 57.08 \\
105 & 742.5 & 2.940 & 14.58 & 61.02 \\
110 & 709.0 & 3.550 & 16.37 & 63.75 \\
115 & 678.0 & 4.110 & 17.94 & 65.80 \\
120 & 650.0 & 4.640 & 19.36 & 67.36 \\
125 & 624.0 & 5.135 & 20.64 & 68.60 \\
130 & 600.0 & 5.600 & 21.80 & 69.65 \\
135 & 577.5 & 6.040 & & 70.45 \\
\hline
\end{tabular}

TABle 5: Number of noisy modes in Groups A-D and the corresponding TOI.

\begin{tabular}{|c|c|c|c|c|c|c|c|c|}
\hline \multirow{2}{*}{ Thickness variation $\Delta d(\mu \mathrm{m})$} & \multicolumn{4}{|c|}{ Number of noisy modes } & \multicolumn{4}{|c|}{ TOI } \\
\hline & Group A & Group C & Group C & Group D & Group A & Group C & Group C & Group D \\
\hline 85 & 3 & 3 & 3 & 3 & 38.85 & 38.85 & 38.85 & 38.85 \\
\hline 90 & 3 & 2 & 1 & 1 & 41.59 & 30.88 & 30.88 & 28.25 \\
\hline 95 & 3 & 2 & 1 & 1 & 46.44 & 29.37 & 29.37 & 27.01 \\
\hline 100 & 3 & 2 & 3 & 3 & 51.13 & 32.49 & 32.49 & 28.74 \\
\hline 105 & 3 & 2 & 3 & 2 & 56.67 & 30.10 & 30.10 & 33.54 \\
\hline 110 & 5 & 2 & 2 & 2 & 58.04 & 27.72 & 27.72 & 35.64 \\
\hline 115 & 6 & 2 & 3 & 3 & 60.96 & 30.53 & 30.53 & 34.52 \\
\hline 120 & 4 & 2 & 3 & 2 & 52.24 & 32.74 & 32.74 & 30.12 \\
\hline 125 & 3 & 1 & 3 & 1 & 56.13 & 28.47 & 28.47 & 21.41 \\
\hline 130 & 3 & 1 & 3 & 1 & 56.59 & 26.12 & 26.12 & 18.62 \\
\hline 135 & 3 & 1 & 2 & 1 & 64.08 & 25.45 & 25.45 & 15.91 \\
\hline
\end{tabular}

does not influence the frequency distribution of the brake noise. Because the damping ratio decreases slowly with increase in compressive strain, the outline of the brake lining must be heavily narrowed to achieve significant noise reduction.

The noise distribution in Group C (Figure 8) is similar to that in Group B (Figure 7); the noisy modes were concentrated at specific frequencies; however, the effect of increasing the damping ratio of noisy modes by reducing the lining width is more significant than in Group B. Furthermore, a new noisy mode appeared at $5900 \mathrm{~Hz}$ with increase in compressive strain; on reaching a damping ratio threshold of $-0.6 \%$, it turned into a noisy mode in the model with a thickness variation of $100 \mu \mathrm{m}$. Reducing the brakelining width can thus reduce the probability of brake noise more effectively than does narrowing the section outline. 


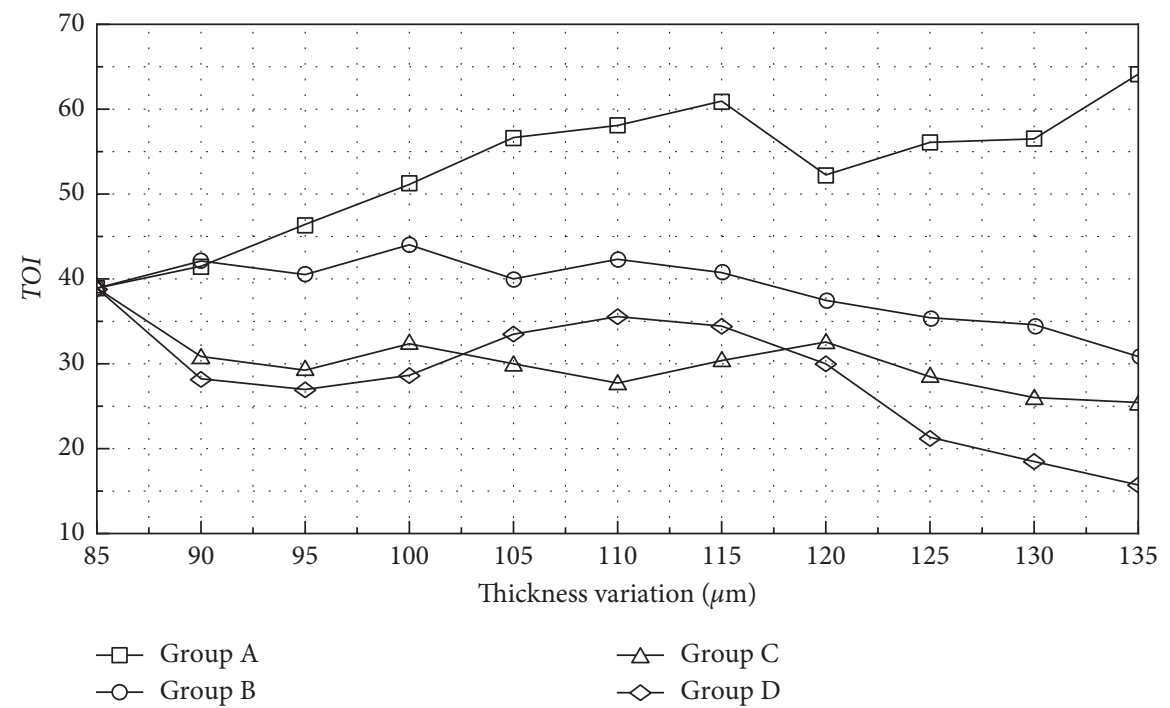

FIgURE 6: TOI curve for each group.

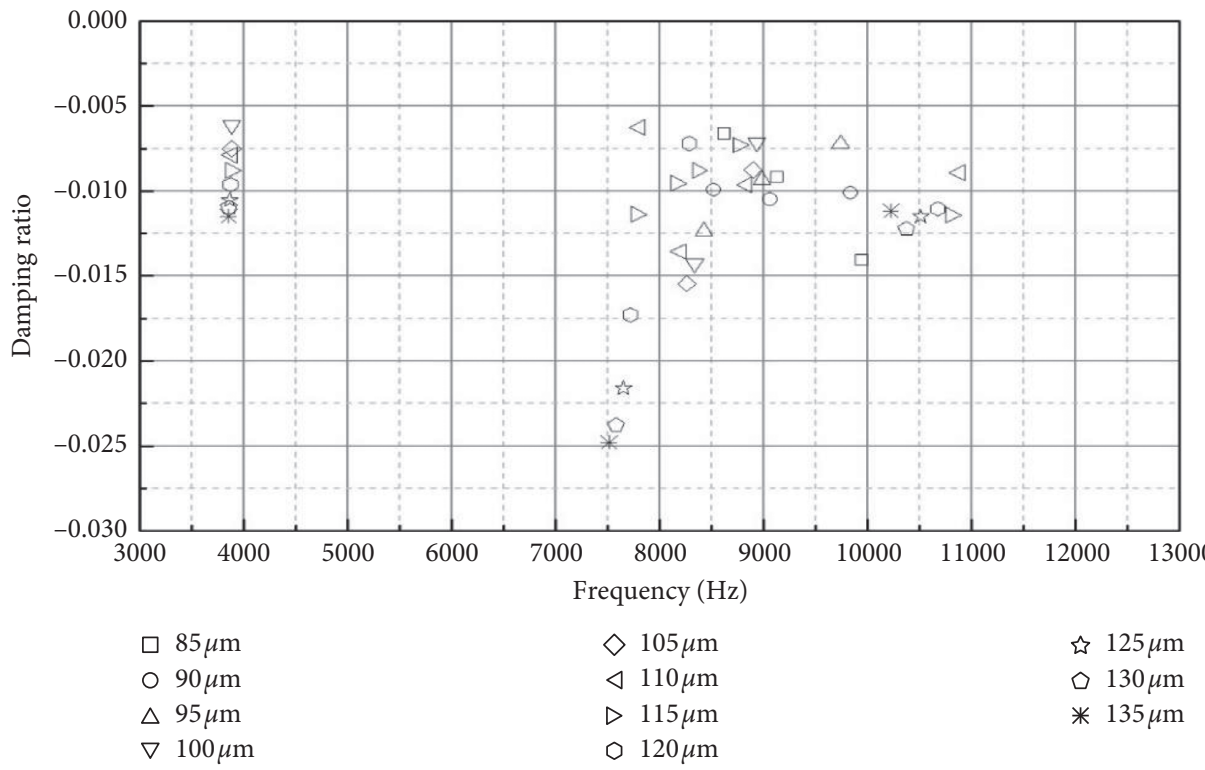

FIgURe 7: Noisy-mode distribution in Group A.

Although the TOI of the model decreased with increase in width reduction, new noisy modes were introduced.

In Group D (Figure 9), the number of noisy modes fluctuated with increasing in compressive strain. The damping ratios of the noisy modes with corresponding frequencies of 8600,9100 , and $9900 \mathrm{~Hz}$ reduced quickly, and the model finally stabilized with further increasing in the compression ratio; the damping ratio of the noisy mode at $5900 \mathrm{~Hz}$ fluctuated markedly in the thickness variation range of $95-120 \mu \mathrm{m}$, which is in agreement with the TOI varying curve of Group D (Figure 6). In addition, a noisy mode appeared at $12400 \mathrm{~Hz}$ when the thickness variation exceeded $95 \mu \mathrm{m}$, but it contributed little to brake noise because its damping ratio was high in all models. Accordingly, the effect of chamfer on brake noise is determined by chamfer size, and the TOI and the distribution of noisy modes could be substantially ameliorated if the chamfer is adequately large; this approach has the strongest effect on noise reduction among all methods of adjusting compressive strain.

\section{Improvement of Brake Pad and Dynamometer Test Verification}

Among the four investigated methods for adjusting the compressive strain of the brake pad, the method of regulating the elastic modulus of friction material is not conducive to the prediction of noise because it significantly changes the distribution of noisy modes; the consequent change in the friction material means that all brake-performance validation must be redone, leading to increased 




Figure 8: Noisy-mode distribution in Group B.

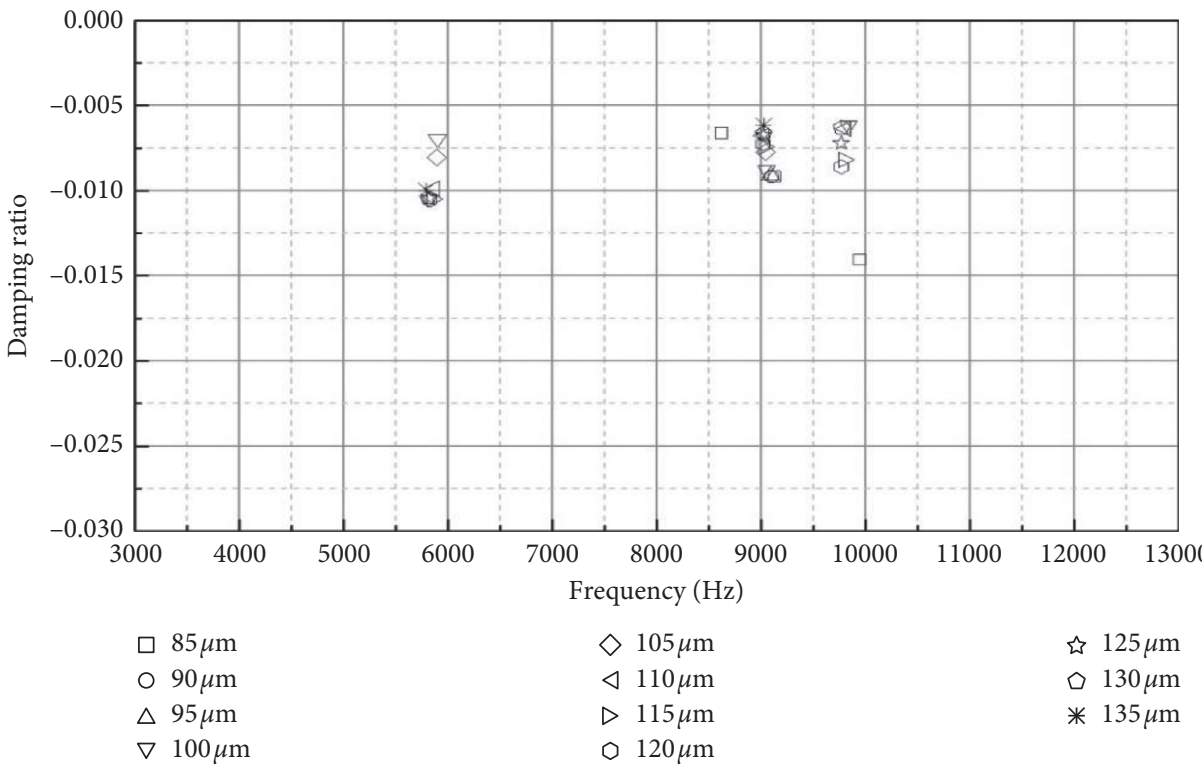

FIgURE 9: Noisy-mode distribution in Group C.

costs and prolonged product-development cycles. The method of narrowing the shape may compromise the shear strength of the brake linings because this approach is only effective when the shape is significantly narrowed. This problem is also encountered in the method of reducing the width of the brake lining. Regarding the method of chamfering brake linings, the reduction in brake noise is strongly dependent on the chamfer size; the model with the largest chamfer exhibited the strongest noise reduction. Because chamfering does not change the contact area of the friction material and backplane, the shear strength of the brake lining is not compromised in this approach.

Setting a large chamfer is thus a reasonable method of adjusting the compressive strain of brake linings to reduce brake noise. A large chamfer reduces the number of noisy modes and increases the damping ratio of the noisy modes, leading to a significant improvement in system stability with little effect on the shear strength of the brake pad. Chamfered brake pads fabricated through this approach are presented in Figure 11. 


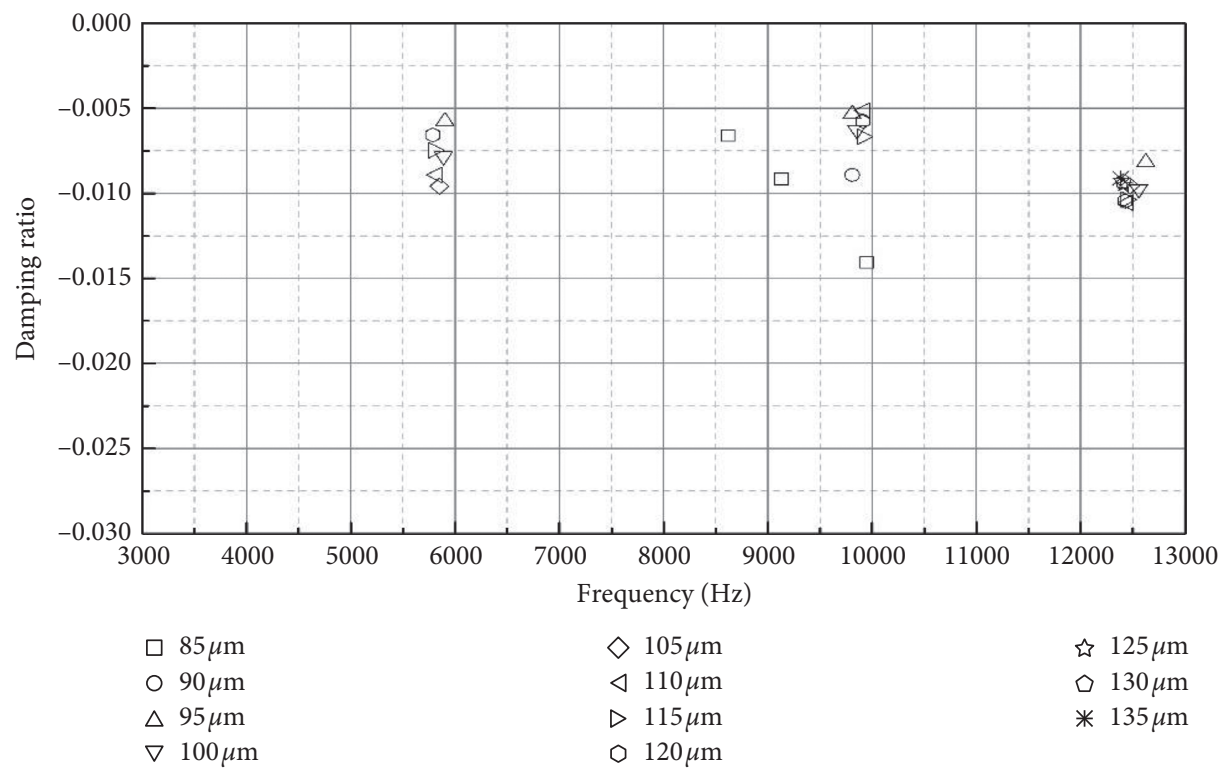

Figure 10: Noisy-mode distribution in Group D.

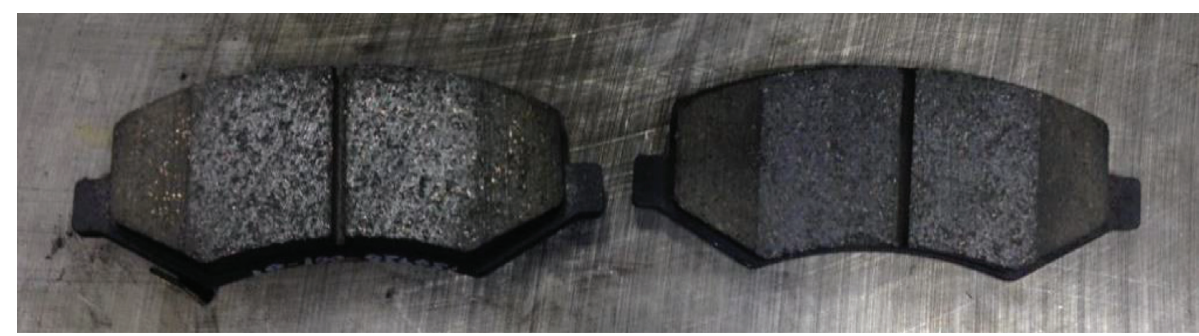

FIGURE 11: Brake pads after chamfering.

TABLE 6: Noise characteristics of brake pads before and after chamfering.

\begin{tabular}{|c|c|c|c|}
\hline Frequency range $(\mathrm{kHz})$ & Noise threshold $(\mathrm{dB})$ & Original pad & Chamfered pad \\
\hline \multirow{2}{*}{$2-16$} & $\geq 70$ & 118 & 6 \\
\hline & $\geq 80$ & 101 & 0 \\
\hline \multirow{2}{*}{$2-4$} & $\geq 70$ & 43 & 1 \\
\hline & $\geq 80$ & 33 & 0 \\
\hline \multirow{2}{*}{$4-6$} & $\geq 70$ & 32 & 0 \\
\hline & $\geq 80$ & 25 & 0 \\
\hline \multirow{2}{*}{$6-10$} & $\geq 70$ & 37 & 0 \\
\hline & $\geq 80$ & 37 & 0 \\
\hline \multirow{2}{*}{$10-14$} & $\geq 70$ & 6 & 5 \\
\hline & $\geq 80$ & 6 & 0 \\
\hline \multirow{2}{*}{$14-16$} & $\geq 70$ & 0 & 0 \\
\hline & $\geq 80$ & 0 & 0 \\
\hline
\end{tabular}

Finally, the cold section most likely to cause brake noise in SAE J2521 was subject to a dynamometer test; the results are summarized in Table 6 .

Of the 460 stops in the test, the brake pads had 118 noisy stops before chamfering, which reduced drastically to 6 after chamfering. The noise distribution in the dynamometer tests of brake linings with and without chamfer is plotted in Figure 12; clearly, the brake noise of the original brake pads mostly appears as a high-sound pressure level with loose frequency distribution, whereas in the chamfered brake pads, the sound pressure level of all brake noise was limited to $80 \mathrm{~dB}$. Overall, the test results confirm that the occurrence 


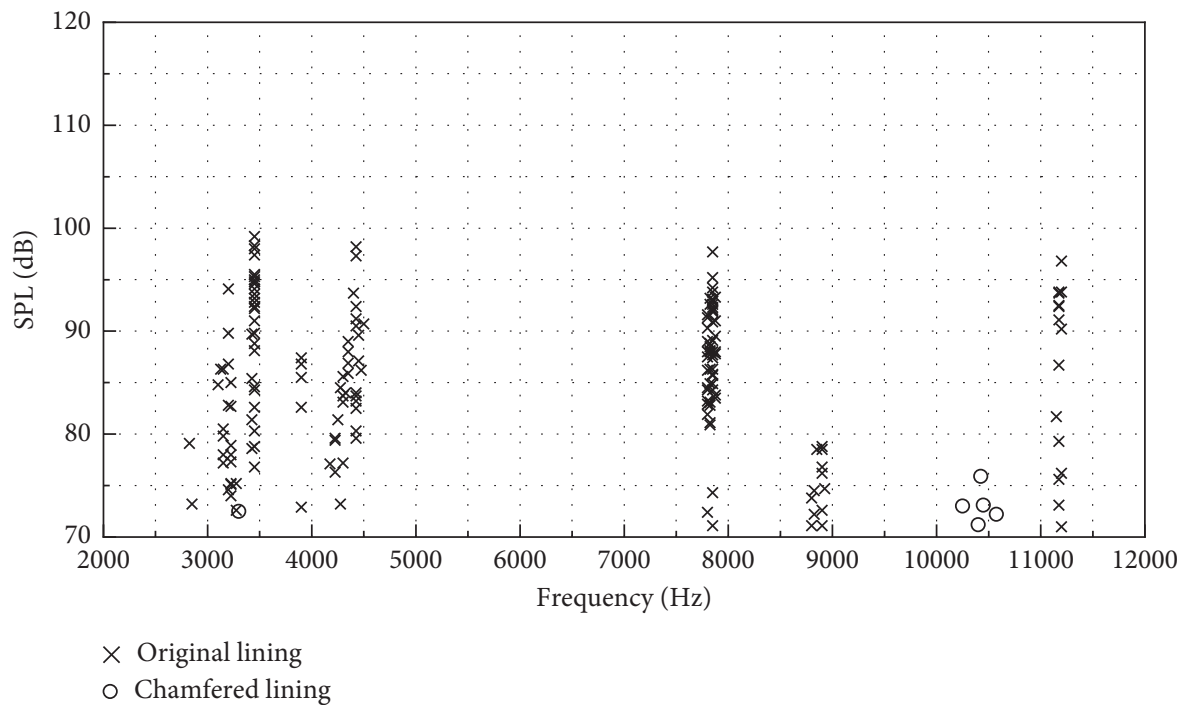

FIGURE 12: Brake-noise distribution of the original and chamfered brake pads.

and intensity of brake noise can be reduced effectively by chamfering the brake linings without changing the friction material or lining shape.

\section{Conclusion}

Through four technical approaches, the compressive strain of a brake pad was adjusted, and the assembly of brake system equipped with pads with different structural and material characteristics was analyzed. Changing the compressive strain of the brake pad effectively influenced the occurrence and frequency distribution of brake noise. The results of the four approaches are summarized herein:

(1) Changing the compression strain of the brake pad will affect the braking noise, but different ways of adjusting compression will produce different effects. Increasing the compressive strain of the brake lining by reducing the elastic modulus of friction material increased the probability of noise during braking; and the probability of brake noise decreased in the methods of narrowing the section outline, reducing the lining width and chamfering the brake pad.

(2) Reducing the elastic modulus of the friction material increased the number of and changed the distribution of noisy modes; moreover, this approach may introduce noisy modes and induce strong instability; and changing the friction material in the development process means that all brake validations need to be redone. Therefore, friction materials with highelasticity modulus should be used to avoid brake noise at the beginning of brake-system design.

(3) Narrowing the section outline or reducing the lining width of the brake pad had little effect on the distribution of noisy modes but could reduce the probability of brake noise. However, the effect can only be represented obviously when the parameters are greatly changed, which lead to the shear strength decrease of the brake pad. Since the loose of strength outweighs the gain of NVH performance, these two approaches are not recommended for brake-noise optimization.

(4) Chamfering the brake pad strongly influenced brakenoise suppression, and this result was validated through dynamometer testing. Because chamfering does not change the contact area of the friction material and backplane, the shear strength of the brake lining is not compromised in this approach. Thus, chamfering the brake pad is a good way for brake-noise optimization.

\section{Data Availability}

The noise data used to support the findings of this study are included within the article.

\section{Conflicts of Interest}

The authors declare that they have no conflicts of interest.

\section{References}

[1] D. P. Wang, J. S. Cao, and W. Z. Liu, "Noise analysis of disc brake for automobile," Applied Mechanics and Materials, vol. 483, pp. 271-274, 2013.

[2] M. S. Qatu, "Recent research on vehicle noise and vibration," International Journal of Vehicle Noise and Vibration, vol. 8, no. 4, pp. 289-301, 2012.

[3] L.-J. Zhang, K. Diao, D.-J. Meng, and M. Pang, "Frictioninduced vibration and noise research: the status quo and its prospect," Journal of Tongji University (Natural Science), vol. 41, no. 5, pp. 765-772, 2013.

[4] G. D. Liles, "Analysis of Disc Brake Squeal Using Finite Element Methods," SAE Technical Paper, SAE International, Troy, MI, USA, 1989, https://saemobilus.sae.org/content/ 891150/. 
[5] M. Dezi, P. Forte, and F. Frendo, "Motorcycle brake squeal: experimental and numerical investigation on a case study," Meccanica, vol. 49, no. 4, pp. 1011-1021, 2014.

[6] G.-Y. Pan, Z.-W. Jiang, Z.-J. Yang, and L. Sun, "Study on contribution of back plate shape of brake pad to disc brake system noise," in Proceedings of the 2015 4th International Conference on Sustainable Energy and Environmental Engineering (ICSEEE 2015), vol. 53, pp. 702-709, Shenzhen, China, January 2016.

[7] M. S. Xie, G. R. Zhang, J. H. Li, and R. Fritsch, "Brake pad taper wear on brake moan noise," International Journal of Automotive Technology, vol. 15, no. 4, pp. 565-571, 2014.

[8] S. Oberst and J. C. S. Lai, "Statistical analysis of brake squeal noise," Journal of Sound and Vibration, vol. 330, no. 12, pp. 2978-2994, 2011.

[9] M. Triches Jr., S. N. Y. Gerges, and R. Jordan, “Analysis of brake squeal noise using the finite element method: a parametric study," Applied Acoustics, vol. 69, no. 2, pp. 147-162, 2008.

[10] M. Esgandari, R. Taulbut, and O. Olatunbosun, "Effect of damping in complex eigenvalue analysis of brake noise to control over-prediction of instabilities: an experimental study," in Proceedings of the Conference: SAE 2013 Brake Colloquium \& Exhibition - 31st Annual, Jacksonville, FL, USA, September 2013.

[11] P. Liu, H. Zheng, C. Cai et al., "Analysis of disc brake squeal using the complex eigenvalue method," Applied Acoustics, vol. 68, no. 6, pp. 603-615, 2007.

[12] C. Vayssière, L. Baillet, V. Linck, and Y. Berthier, "Influence of contact geometry and third body on squeal initiation: experimental and numerical studies," in Proceedings of the World Tribology Congress III, vol. 1, pp. 363-364, Washington, D.C., USA, September 2005.

[13] ISO, Road Vehicles - Brake Linings - Compressive Strain Test Methods, International Organization for Standardization, Geneva, Switzerland, 2009.

[14] H. Lü and D. Yu, "Brake squeal reduction of vehicle disc brake system with interval parameters by uncertain optimization," Journal of Sound and Vibration, vol. 333, no. 26, pp. 73137325, 2014.

[15] H. Lü and D.-J. Yu, "Uncertainty optimization of vehicle brakes based on interval analysis," International Journal of Automotive Engineering, vol. 37, no. 7, pp. 807-812, 2015.

[16] S. Oberst, J. C. S. Lai, and S. Marburg, "Guidelines for numerical vibration and acoustic analysis of disc brake squeal using simple models of brake systems," Journal of Sound and Vibration, vol. 332, no. 9, pp. 2284-2299, 2013.

[17] M. Esgandari, O. Olatunbosun, and R. Taulbut, "Frictional coefficient distribution pattern on brake disk-pad contact interface to reduce susceptibility of brake noise instabilities causing brake squeal," in Proceedings of the Conference: EuroBrake 2013, Dresden, Germany, May 2013.

[18] S.-K. Yang, Z. Sun, Y.-J. Liu, B.-W. Lu, T. Liu, and H.-S. Hou, "Automotive brake squeal simulation and optimization," $S A E$ International Journal of Passenger Cars - Mechanical Systems, vol. 9, no. 1, pp. 174-182, 2016.

[19] SAE International, Disc and Drum Brake Dynamometer Squeal Noise Test Procedure, SAE International, Warrendale, Pennsylvania, USA, 2013.

[20] D.-H. Guan and D.-Y. Jiang, "A Study on Disc Brake Squeal Using Finite Element Methods," SAE Technical Paper, SAE International, Troy, MI, USA, 1998, https://saemobilus.sae. org/content/980597/. 